\title{
KAJIAN PENERAPAN TATA KELOLA TEKNOLOGI INFORMASI DENGAN MENGGUNAKAN COBIT 4.0 STUDI KASUS PT. SURYA MADISTRINDO PANGKALPINANG
}

\author{
Lili Indah Sari \\ Program Studi Sistem Informasi,STMIK Atma Luhur Pangkalpinang \\ Jl. Jend.Sudirman-Selindung Lama Pangkalpinang \\ Email : wishlie 28@yahoo.co.id
}

\begin{abstract}
Abstrak
Tata kelola teknologi informasi pada proses pengelolaan data adalah manajemen pengelolaan data yang merupakan aset penting bagi perusahaan ataupun organisasi. Langkah-langkah perbaikan yang berkelanjutan (continous improvement) terhadap tata kelola teknologi informasi khususnya pada proses pengelolaan data diharapkan akan mampu meminimalisasi risiko ancaman di atas. Kajian penerapan tata kelola teknologi informasi dengan menggunakan cobit framework 4.0 dilakukan dengan menggunakan 4 domain yang ada yaitu Plan and Organization, Aquire and Implement, Delivery and support serta Monitor and evaluate. Dari sinilah penulis dapat mengetahui tingkat kematangan atau maturity level.
\end{abstract}

Kata Kunci : Tata kelola, COBIT, ,Maturity Level, Plan and Organization, Aquire and Implement, Delivery and support serta Monitor and evaluate

\section{PENDAHULUAN}

Pesatnya kemajuan dan perkembangan zaman pada saat ini tidak terlepas dari perkembangan dan keterlibatan teknologi informasi dan komunikasi atau yang juga dikenal dengan TIK. Teknologi informasi menyebabkan peran komputer begitu diperlukan dalam berbagai aspek kehidupan manusia. Perkembangan teknologi informasi dan komunikasi memberikan peluang inovasi produk dan layanan berbasis teknologi informasi bagi suatu organisasi atau perusahaan. Penerapan TIK harus disesuaikan dengan kebutuhan atau institusi agar dapat mencapai tujuan institusi tersebut. Untuk mencapai tujuan institusi tersebut diperlukan suatu perencanaan dan implementasi teknologi informasi yang selaras dengan perencanaan dan strategi bisnis organisasi yang telah didefinisikan.

Tata kelola teknologi informasi pada proses pengelolaan data yang kurang baik akan menimbulkan beberapa permasalahan yang merupakan kelemahan (vulnerabilities) sehingga akan menimbulkan ancaman (threats) seperti kejadian kehilangan, perusakan, pencurian dan penyadapan data penting perusahaan atau organisasi. Tata kelola teknologi informasi pada proses pengelolaan data adalah manajemen pengelolaan data yang merupakan aset penting bagi perusahaan ataupun organisasi. Langkah-langkah perbaikan yang berkelanjutan (continous improvement) terhadap tata kelola teknologi informasi khususnya pada proses pengelolaan data diharapkan akan mampu meminimalisasi risiko ancaman di atas.

PT. Surya Madistrindo adalah subsidiary dari PT Gudang Garam Tbk yang berada di pangkalpinang yang bergerak dibidang pendistribusian rokok produk PT. Gudang Garam, Tbk. Untuk membantu proses bisnisnya PT.Surya Madistrindo memerlukan suatu sistem yang terintegrasi demi kelancaran proses bisnisnnya. Dalam hal ini, metode pengelolaan tata kelola teknologi informasi yang baik perlu diterapkan dalam pengelolaan perusahaan. sehingga penggunaan teknologi informasi tersebut dapat mendukung tercapainya tujuan strategis, PT. Surya Madistrindo. Penelitian ini akan membahas sejauh mana tingkat kematangan terhadap tata kelola teknologi informasi yang ada pada PT. Surya Madistrindo yang merupakan subsidiary dari PT Gudang Garam Tbk yang berada di pangkalpinang. Karena tata kelola teknologi informasi sangat diperlukan diantaranya untuk tetap menjaga investasi, meningkatkan daya saing, serta menjaga keberlangsungan bisnis proses yang ada - COBIT (Control Objectives for Information and Related Technology) adalah kerangka Tata Kelola TI (IT Governance framework) yang banyak dipakai oleh praktisi, merupakan salah satu alat yang digunakan untuk pengelolaan teknologi informasi, yaitu suatu model standar yang menyediakan dokumentasi best practice pengelolaan TI. 


\subsection{Rumusan Masalah}

Berdasarkan latar belakang diatas maka diperoleh dua rumusan masalah untuk melakukan penelitian tentang Kajian Penerapan tata kelola teknologi informasi dengan menggunakan COBIT framework 4.0 yang ada pada PT. Surya Madistrindo, karena belum memiliki

PT. Surya Madistrindo belum memiliki prosedur pengelolaan teknologi informasi yang baik untuk itu diperlukan suatu penerapan tata kelola tenologi informasi yang dapat membantu meningkatkan proses bisnis, untuk tetap menjaga investasi, meningkatkan daya saing, serta menjaga keberlangsungan bisnis proses yang ada. Oleh karena itu peneliti melakukan penelitian tentang Kajian Penerapan tata kelola teknologi informasi dengan menggunakan COBIT framework 4.0 yang ada pada PT. Surya Madistrindo. Adapun rumusan masalah yaitu Bagaimana penerapan tatakelola Teknologi Informasi pada PT. Surya Madistrindo agar perusahaan menjadi lebih maju khususnya dalam penggunaan teknologi informasi

Untuk mengetahui sejauh mana tingkat kematangan (Maturity Level) tata kelola teknologi informasi yang dilakukannya.

\subsection{Pembatasan masalah}

Untuk memfokuskan penelitian maka peneliti menggunakan COBIT framework 4.0 dengan menggunakan 15 kerangka kerja yang ada.

\subsection{Tujuan dan Manfaat Penelitian}

Adapaun tujuan dan manfaat penelitian ini:

a. Untuk mengetahui seberapa besar penerapan tata kelola teknologi informasi dalam perusahaan dan di level manakah tingkat kematangan dalam pengelolaan tata kelola teknologi informasi yang ada.

b. Memberikan penilaian dan arahan yang berorientasi pada bisnis dengan menggunakan standar COBIT terhadap kebutuhan pengendalian bagi pihak manajemen.

c. Proses dan hasil penelitian dapat dijadikan arah untuk menuju penerapan pengelolaan TI yang lebih baik bagi PT. Surya Madistrindo Pangkalpinang.

\section{TINJAUAN PUSTAKA}

\subsection{Pengertian Tata Kelola Teknologi Informasi (IT Governance)}

Pengertian IT governance menurut ITGI (2003, p.10): $:^{[3]}$

IT governance is the responsibility of the board of directors and excecutive management. IT is an integral part of enterprise governance and consists of the leadership and orgazinational structures and processes that ensure that the organization's TI sustains and extends the organization's strategies and objectives.

Dari definisi tersebut dijelaskan bahwa IT governance merupakan tanggung jawab dari pimpinan puncak dan eksekutif manajemen dari suatu perusahaan, terdiri dari kepemimpinan dan struktur organisasi dan proses yang ada adalah untuk memastikan kelanjutan TI organisasi dan pengembangan strategi dan tujuan dari organisasi. Sementara menurut [Weill 2004], MIT menyatakan bahwa tata kelola TI harus mampu mengarahkan prilaku penggunaan TI sesuai dengan prilaku yang diinginkan atau ditetapkan. Hal yang dimaksud dengan prilaku yang diinginkan adalah prilaku yang sesuai dengan visi, misi, nilai-nilai, strategi dan budaya organisasi. Sedangkan menurut Grembeergen, Haes, \& Guldentops (2004, p 5). Governance. IT governance adalah: IT governance is the organizational capacity excercised by the Board, excecutive management and IT management to control the formulation and implementation of IT strategy and in this way ensure the fusion of business and IT.

Dari pengertian tersebut tata kelola teknologi informasi merupakan tindakan organisaional yang dilakukan oleh dewan, manajemen eksekutif dan manajemen TI untuk mengendalikan formulasi dan implementasi dari strategi TI dan caranya untuk meyakini bisnis dan TI itu sendiri.

Tujuan diterapkannya tata kelola TI dalam suatu organisasi meliputi tujuan jangka pendek dan jangka panjang sebagai berikut.

a. Jangka pendek, yaitu tata kelolanTI digunakan untuk menekan biaya operasional TI dengan mengoptimalkan operasi-operasi yang ada di dalamnya melalui pengendalian pada setiap proses pengguna sumber daya TI dan penanganan resiko yang terkait dengan TI.

b. Jangka panjang, yaitu tata kelola TI membantu perusahaan untuk tetap fokos terhadap nilai strategis penerapan TI dan memastikan peranan TI dapat dukungan pencapaian tujuan perusahaan.

Sedangkan Menurut Information Technology Governance Institute (ITGI) dalam CISA Review Manual 2009, ${ }^{[3]}$ Tata kelola TI (IT Governance) merupakan struktur dari hubungan dan proses yang mengarahkan dan mengatur organisasi dalam rangka mencapai tujuannya dengan memberikan nilai tambah dari pemanfaatan TIK dan melakukan penyeimbangan risiko dengan hasil yang diberikan oleh TIK dan prosesnya. Ada 
sembilan tugas yang berada dalam area Tata Kelola TI, yaitu:

1. Melakukan evaluasi atas efektifitas struktur Tata Kelola TI untuk memastikan adanya kontrol yang cukup terhadap keputusan, arahan dan performa dari TI agar dapat mendukung strategis dan tujuan dari organisasi.

2. Melakukan evaluasi struktur organisasi TI dan manajemen sumber daya untuk memastikan bahwa mereka mendukung strategis dan tujuan organisasi.

3. Melakukan evaluasi strategi TI dan proses untuk pengembangan, persetujuan, implementasi, dan pemeliharaan untuk memastikan bahwa mereka mendukung strategis dan tujuan organisasi.

4. Melakukan evaluasi atas kebijakan, standar, prosedur, dan proses organisasi TI untuk pengembangan, persetujuan, implementasi dan pemeliharaan dalam memastikan dukungan strategi TI dan memenuhi peraturan dan kebutuhan undang-undang.

5. Melakukan evaluasi praktek manajemen untuk memastikan kepatuhan atas strategi, kebijakan, standar, dan prosedur organisasi TI.

6. Melakukan evaluasi investasi sumber daya TI, penggunaannya dan praktek pengalokasian untuk memastikan strategis organisasi dan tujuan sudah sesuai.

7. Melakukan evaluasi kontrak strategis dan kebijakan serta praktek kontrak manajemen untuk memastikan bahwa mereka mendukung strategis dan tujuan organisasi.

8. Melakukan evaluasi praktek manajemen risiko untuk memastikan risiko-risiko terkait di organisasi TI dikelola dengan baik.

9. Melakukan evaluasi monitoring dan assurance practices untuk memastikan dewan dan manajemen eksekutif menerima informasi yang tepat dan memadai atas performa TI.

\subsection{COBIT ( Control objectives for Information and Related Technology) \\ COBIT pertama sekali diperkenalkan pada} tahun 1996 adalah merupakan alat (tool) yang disiapkan untuk mengatur teknologi informasi (IT Governance tool). COBIT telah dikembangkan sebagai sebuah aplikasi umum dan telah diterima menjadi standar yang baik bagi praktek pengendalian dan keamanan TI yang menyediakan sebuah kerangka kerja bagi pengelola, user, audit sistem informasi, dan pelaksana pengendalian dan keamanan. Sedangkan COBIT versi 4.0 dirilis pada Desember tahun 2005.
Control Objective for Information and Related Technologi (COBIT) dapat diartikan sebagai tujuan pengendalian untuk informasi dan teknologi terkait dan merupakan standar terbuka untuk pengendalian terhadap teknologi informasi yang dikembangkan dan dipromosikan oleh Institut IT Governance.

\subsection{Kerangka kerja COBIT}

Kerangka kerja COBIT khusus versi 4.0 penentu kendali dalam TI berdasarkan informasi yang dibutuhkan untuk mendukunga tujuan bisnis dan informasi yang dihasilkan dari gabungan penerapan proses TI dan sumberdaya terkait. Terdiri dari 4 kerangka kerja yang ada yaitu Control Objective, Audit Guidelines,Management guidelines, dan Maturity Models. Sedangkan dalam Control Objective terdiri dari 4 tujuan pengendalian tingkat tinggi yang tercermin di dalam 4 domain antara lain ; Planning and Organization , Acquisition \& Implementation, Delivery \& Support, Monitoring \& Evaluation Untuk dapat memahami kerangka kerja COBIT, perlu diketahui bahwa COBIT mempunyai karakteristik utama. Adapun karakteristik utama dari kerangka kerja COBIT adalah focus pada bisnis, orientasi pada proses, berbasis kontrol dan dikendalikan oleh pengukuran.

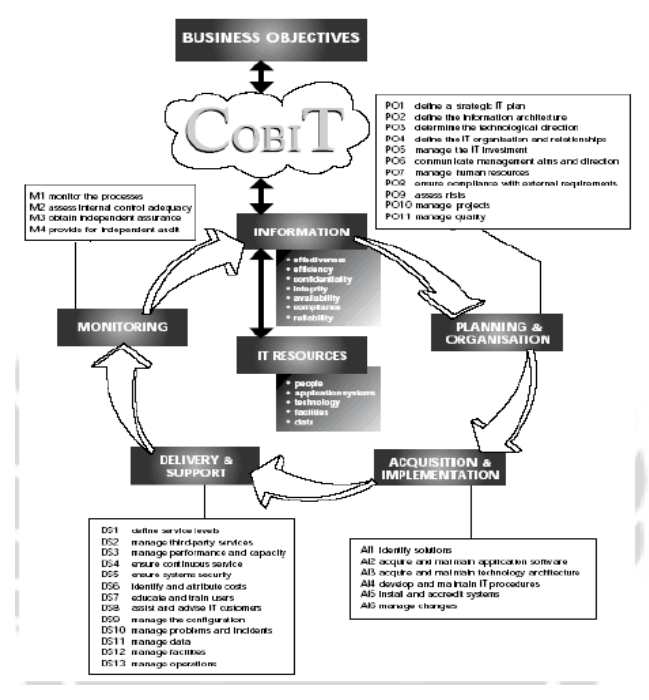

Gambar 1. Kerangka Kerja Cobit 4.0

\subsection{Maturity Models}

Maturity Model Merupakan merupakan alat bantu bagi perusahaan / pihak pengelola untuk melakukan self assessment pengelolaan TI yang diterapkan COBIT mempunyai model kematangan untuk mengontrol proses-proses TI dengan menggunakan metode penilaian / scoring sehingga organisasi dapat menilai proses-proses TI yang dimilikinya. Maturity model dapat digunakan untuk memetakan : 
a. Status pengelolaan TI perusahaan pada saat itu

b. Status standart industri dalam bidang TI saat ini (sebagai pembanding)

c. Status standart internasional dalam bidang TI saat ini (sebagai pembanding)

d.Strategi pengelolaan TI perusahaan (ekspetasi perusahaan terhadap posisi pengelolaan TI perusahaan)

Ada 6 tingkatan level maturity dalam pengelolaan TI yaitu :

a. Level 0 (Non-existent)

b. Level 1 (Initial Level)

c. Level 2 (Repeatable Level)

d. Level 3 (Defined Level)

e. Level 4 (Managed Level)

f. Level 5 (Optimized Level)

Jika digambarkan grafik skalanya yaitu :

Inital/ Repeatable Defined Managed and

Non-existent AdHoc butlntuitive Process Measurable Optimised

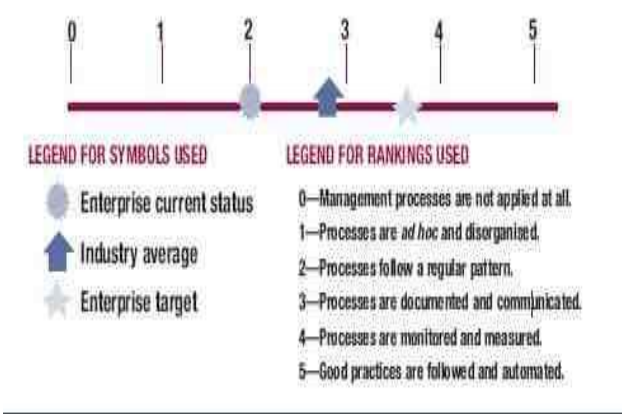

Gambar2. Grafik Representasi model skala maturity ([ITGI 2005],18)

Dengan adanya maturity level models, maka organisasi dapat mengetahui posisi kematangan tata kelola teknologi informasinya, Semakin optimal suatu organisasi dalam mengelola sumber daya teknologi informasinya, Akan semakin tinggi nilai akhir tingkat kematangan yang diperoleh

\section{METODE PENELITIAN}

Penelitian survie merupakan usaha untuk mengamati, mendapatkan informasi yang jelas terhadap suatu masalah tertentu dalam suatu penelitian. Dalam penelitian ini, data dikumpulkan dari responden dengan menggunakan kuesioner.

\subsection{Metode Pemilihan Sample}

Metode penarikan sample yang digunakan dalam penelitian ini adalah tehnik purposive sampling, yaitu sample yang diambil dengan maksud atau tujuan tertentu. Purposive sampling adalah teknik penentuan sampel untuk tujuan tertentu saja. Purposive sampling juga bisa berarti sampling yang menentukan target kelompok tertentu.Disini penulis mengambil data dari populasi yang terbatas. Responden yang diambil dari sample ini adalah responden ahli yang berasal dari pemangku kepentingan perusahaan

\subsection{Instrumentasi}

Penelitian ini menggunakan instrumentasi dalam bentuk kuesioner. Pernyataan kuesioner dikembangkan berdasarkan jumlah pernyataan atau statement pada tingkat maturity di setiap control objective, pada domain :
a. Plan and Organise (PO
b. Aquire and Implement (AI
c. Delivery and Support (DS

d. Monitor and Evaluate (ME)

Yang ada pada 15 kerangka kerja COBIT framework 4.0 yang telah ditentukan.

Tabel 1. Jumlah Pernyataan Pada Domain Planing And Organization (PO)

\begin{tabular}{|c|c|c|c|c|c|c|c|}
\hline \multirow{2}{*}{ Domain } & \multicolumn{6}{|c|}{ Level Maturity } & \multirow{2}{*}{$\begin{array}{l}\text { Total } \\
\text { Perny } \\
\text { ataan } \\
\end{array}$} \\
\hline & 0 & 1 & 2 & 3 & 4 & 5 & \\
\hline PO1 & 0 & 7 & 6 & $\begin{array}{l}1 \\
2 \\
\end{array}$ & 9 & 4 & 38 \\
\hline PO3 & 1 & 7 & 7 & 9 & $\begin{array}{l}1 \\
1 \\
\end{array}$ & 9 & 44 \\
\hline PO5 & 3 & 5 & 7 & 9 & 9 & 6 & 39 \\
\hline PO9 & 0 & $\begin{array}{l}1 \\
0 \\
\end{array}$ & 0 & 7 & $\begin{array}{l}1 \\
5 \\
\end{array}$ & 7 & 39 \\
\hline PO10 & 0 & 6 & 9 & $\begin{array}{l}1 \\
0\end{array}$ & $\begin{array}{l}1 \\
2 \\
\end{array}$ & 5 & 42 \\
\hline & & & & & & & 202 \\
\hline
\end{tabular}

Tabel 2. Jumlah Pernyataan Pada Domain Acquisition And Implementation (AI)

\begin{tabular}{|c|c|c|c|c|c|c|c|}
\hline \multirow[b]{2}{*}{ Domain } & \multicolumn{6}{|c|}{ Level Maturity } & \multirow{2}{*}{$\begin{array}{l}\text { Tota } \\
\text { l } \\
\text { Pern } \\
\text { yata } \\
\text { an } \\
\end{array}$} \\
\hline & 0 & 1 & 2 & 3 & 4 & 5 & \\
\hline AI1 & 2 & 8 & 8 & 5 & 9 & 8 & 40 \\
\hline $\mathrm{AI} 2$ & 2 & 8 & 6 & 7 & 2 & 6 & 31 \\
\hline AI5 & 2 & 6 & 7 & 9 & 8 & 7 & 39 \\
\hline AI6 & 3 & 5 & 3 & 4 & 9 & 5 & 29 \\
\hline \multicolumn{7}{|c|}{$\begin{array}{lll}\text { Jumlah Pernyataan } & \text { dalam } \\
\text { domain AI } & & \\
\end{array}$} & 139 \\
\hline
\end{tabular}

Tabel 3. Jumlah Pernyataan Pada Domain Delivery And Support (DS)

\begin{tabular}{|c|c|c|c|c|c|c|c|}
\hline \multirow[b]{2}{*}{ Domain } & \multicolumn{6}{|c|}{ Level Maturity } & \multirow{2}{*}{$\begin{array}{l}\text { Total } \\
\text { Pern } \\
\text { yataa } \\
\text { n }\end{array}$} \\
\hline & $\mathbf{0}$ & 1 & 2 & 3 & 4 & 5 & \\
\hline DS1 & 0 & 3 & 7 & 7 & 9 & 4 & 30 \\
\hline DS4 & 3 & 7 & 6 & 7 & 2 & 9 & 44 \\
\hline
\end{tabular}




\begin{tabular}{|l|l|l|l|l|l|l|l|} 
& 5 & 7 & 9 & 1 & 1 & 1 & $\mathbf{5 6}$ \\
\hline DS5 5 10 & 2 & 3 & 4 & 8 & 6 & 6 & $\mathbf{2 9}$ \\
\hline DS11 & 5 & 4 & 9 & 1 & 8 & 9 & $\mathbf{4 7}$ \\
\hline $\begin{array}{l}\text { Jumlah Pernyataan } \\
\text { domain DS }\end{array}$ & dalam & $\mathbf{2 0 6}$ \\
\hline
\end{tabular}

Tabel 4. Jumlah Pernyataan Pada Domain Monitoring And Evaluation (ME)

\begin{tabular}{|c|c|c|c|c|c|c|c|}
\hline \multirow{2}{*}{ Domain } & \multicolumn{6}{|c|}{ Level Maturity } & \multirow{2}{*}{$\begin{array}{l}\text { Total } \\
\text { Pernyataa } \\
\text { n } \\
\end{array}$} \\
\hline & $\mathbf{0}$ & 1 & 2 & 3 & 4 & 5 & \\
\hline ME1 & 4 & 5 & 3 & 4 & 5 & 6 & 27 \\
\hline \multicolumn{7}{|c|}{$\begin{array}{l}\text { Jumlah Pernyataan dalam } \\
\text { domain ME }\end{array}$} & 27 \\
\hline
\end{tabular}

\subsection{Metode Pengumpulan Data}

Pengumpulan data penelitian dilakukan dengan cara pengisian kuesioner untuk memperoleh data sesuai dengan tujuan penelitian, dalam hal ini item pertanyaan yang diajukan dengan model pertanyaan yang ada pada standar COBIT. Kuesioner merupakan teknik pengumpulan data yang dilakukan dengan cara menyajikan berbagai pertanyaan tertulis pada responden atau obyek penelitian untuk dijawab sebagai fakta dalam penelitian. Setelah itu peneliti membuat skor dari hasil jawaban yang telah diperoleh untuk dilanjutkan pada analisa data. Instrument atau daftar pertanyaan yang diberikan pada responden merupakan hasil pengembangan dari variabelvariabel penelitian

\subsection{Teknik Analisis Data}

Penelitian ini menggunakan teknik analisis data secara kuantitatif dan deskriptif. Teknik analisis kuantitatif menggunakan spreadsheet Microsoft Excel untuk mengolah untuk menjawab dan menjelaskan perumusan masalah tingkat kematangan (maturity level). Tata kelola teknologi informasi yang dilakukan di PT. Surya Madistrindo. Data yang diterima dari responden, dengan menggunakan skala Guttman, akan diolah dengan menggunakan perhitungan rata-rata sehingga mendapatkan tingkat kematangan rata-rata dan chart radar. Dari chart radar tersebut akan terlihat sebaran tingkat kematangan PT. Surya Madistrindo saat ini, pada 15 proses kerangka kerja COBIT 4.0

\section{HASIL DAN PEMBAHASAN}

4.1 Hasil Perhitungan Level Pertiap Domain Yang Ada Untuk Domain PO (Plan and Organise)
Tabel 5. Rekapitulasi Hasil Perhitungan Tingkat Kematangan TI Domain PO

\begin{tabular}{|c|l|c|c|}
\hline Domain & PROSES & $\begin{array}{l}\text { Current } \\
\text { Maturity }\end{array}$ & $\begin{array}{c}\text { Expected } \\
\text { Maturity }\end{array}$ \\
\hline PO1 & $\begin{array}{l}\text { Define a } \\
\text { strategic IT } \\
\text { plan }\end{array}$ & 2.826 & 3 \\
\hline PO3 & $\begin{array}{l}\text { Determine } \\
\text { technologic } \\
\text { al direction }\end{array}$ & 2.765 & 3 \\
\hline PO5 & $\begin{array}{l}\text { Manage the } \\
\text { IT } \\
\text { investment }\end{array}$ & 2.396 & 2 \\
\hline PO9 & $\begin{array}{l}\text { Assess and } \\
\text { manage IT } \\
\text { Risk }\end{array}$ & 3.106 & 3 \\
\hline PO10 & $\begin{array}{l}\text { Manage } \\
\text { projects }\end{array}$ & 3.059 & 3 \\
\hline
\end{tabular}

\subsection{Domain AI}

Tabel 6. Rekapitulasi Hasil Perhitungan Tingkat Kematangan TI Domain AI

\begin{tabular}{|l|l|l|l|}
\hline Domain & Proses & $\begin{array}{l}\text { Curent } \\
\text { Maturity }\end{array}$ & $\begin{array}{l}\text { Expected } \\
\text { Maturity }\end{array}$ \\
\hline AI1 & $\begin{array}{l}\text { Identify } \\
\text { automated } \\
\text { solution }\end{array}$ & 2.306 & 2 \\
\hline AI2 & $\begin{array}{l}\text { Acquire } \\
\text { and } \\
\text { maintain } \\
\text { application } \\
\text { software }\end{array}$ & 2.537 & 3 \\
\hline AI5 & $\begin{array}{l}\text { Procure IT } \\
\text { Resources }\end{array}$ & 2.356 & 2 \\
\hline AI6 & $\begin{array}{l}\text { Manage } \\
\text { changes }\end{array}$ & 2.414 & 2 \\
\hline
\end{tabular}

\subsection{Domain DS dan ME}

Tabel 7. Rekapitulasi Hasil Perhitungan Tingkat Kematangan TI Domain DS

\begin{tabular}{|c|c|c|c|}
\hline Domain & Proses & $\begin{array}{l}\text { Curent } \\
\text { Maturity }\end{array}$ & $\begin{array}{l}\text { Expected } \\
\text { Maturity }\end{array}$ \\
\hline DS1 & $\begin{array}{l}\text { Define and } \\
\text { manage service } \\
\text { levels }\end{array}$ & 2.619 & 3 \\
\hline DS4 & $\begin{array}{l}\text { Ensure } \\
\text { continuous } \\
\text { service }\end{array}$ & 2.306 & 2 \\
\hline DS5 & $\begin{array}{l}\text { Ensure systems } \\
\text { security }\end{array}$ & 2.537 & 2 \\
\hline DS10 & $\begin{array}{l}\text { Manage } \\
\text { problems }\end{array}$ & 2.356 & 2 \\
\hline DS11 & Manage data & 2.414 & 2 \\
\hline ME1 & $\begin{array}{l}\text { Monitor and } \\
\text { evaluate } I T \\
\text { performance }\end{array}$ & 2.490 & 2 \\
\hline
\end{tabular}


4.4 Hasil Evaluasi Maturity Level ProsesProses TI Dalam Tata Kelola TI Di PT.Surya Madistrindo

Dari hasil perhitungan yang telah dilakukan penulis dengan menggunakan software MS.Excel , dimana tingkat kematangan yang menjadi acuan dalam penelitian ini berdasarkan 15 kerangka kerja yang ada COBIT 4.0 pada setiap domainnya yaitu Plan and Organise (PO) yang terdiri dari 173 pertanyaan, Aquire and Implement (AI) yang terdiri dari 109 pertanyaan, Delivery and Support (DS)terdiri dari 186 pertanyaan, dan Monitor and Evaluate (ME) 33 pertanyaan pada 15 kerangka kerja yang telah ditentukan.

Tabel dibawah ini merupaka hasil perhitungan keseluruhan domain untuk menilai tingkat kematangan yang ada

Tabel 8. Hasil Evaluasi Perhitungan Tingkat Kematangan TI Di PT Surya Madistrindo

\begin{tabular}{|c|c|c|c|}
\hline Domain & Proses & $\begin{array}{l}\text { Curent } \\
\text { Maturity }\end{array}$ & $\begin{array}{l}\text { Expected } \\
\text { Maturity }\end{array}$ \\
\hline PO1 & $\begin{array}{lr}\text { Define } & a \\
\text { strategic } & I T \\
\text { plan } & \\
\end{array}$ & 2.489 & 2 \\
\hline PO3 & $\begin{array}{l}\text { Determine } \\
\text { technological } \\
\text { direction }\end{array}$ & 2.229 & 2 \\
\hline PO5 & $\begin{array}{l}\text { Manage the IT } \\
\text { investment }\end{array}$ & 2.450 & 2 \\
\hline PO9 & $\begin{array}{l}\text { Asses and } \\
\text { manage IT Risk }\end{array}$ & 2.241 & 2 \\
\hline PO10 & $\begin{array}{l}\text { Manage } \\
\text { projects }\end{array}$ & 2.619 & 3 \\
\hline AI1 & $\begin{array}{l}\text { Identify } \\
\text { automated } \\
\text { solution }\end{array}$ & 2.306 & 2 \\
\hline $\mathrm{AI} 2$ & $\begin{array}{l}\text { Acquire and } \\
\text { maintain } \\
\text { application } \\
\text { software }\end{array}$ & 2.537 & 3 \\
\hline AI5 & $\begin{array}{ll}\text { Procure } & I T \\
\text { Resources } & \\
\end{array}$ & 2.356 & 2 \\
\hline AI6 & $\begin{array}{l}\text { Manage } \\
\text { changes }\end{array}$ & 2.414 & 2 \\
\hline DS1 & $\begin{array}{l}\text { Define and } \\
\text { manage service } \\
\text { levels }\end{array}$ & 2.619 & 3 \\
\hline DS4 & $\begin{array}{l}\text { Ensure } \\
\text { continuous } \\
\text { service }\end{array}$ & 2.306 & 2 \\
\hline DS5 & $\begin{array}{l}\text { Ensure systems } \\
\text { security }\end{array}$ & 2.537 & 2 \\
\hline DS10 & $\begin{array}{l}\text { Manage } \\
\text { problems }\end{array}$ & 2.356 & 2 \\
\hline DS11 & Manage data & 2.414 & 2 \\
\hline ME1 & $\begin{array}{l}\text { Monitor and } \\
\text { evaluate } \quad I T \\
\text { performance }\end{array}$ & 2.490 & 2 \\
\hline
\end{tabular}

Hasil tingkat kematangan yang ada pada PT Surya Madistrindo Pangkalpinang, selain bisa menggunakan tabel seperti yang diatas, bias juga dengan digambarkan menggunakan grafiknya, maka bias dilihat pada grafik dibawah ini .

\section{Tingkat Kematangan Tatakelola TI pada PT.Surya Madistrindo}
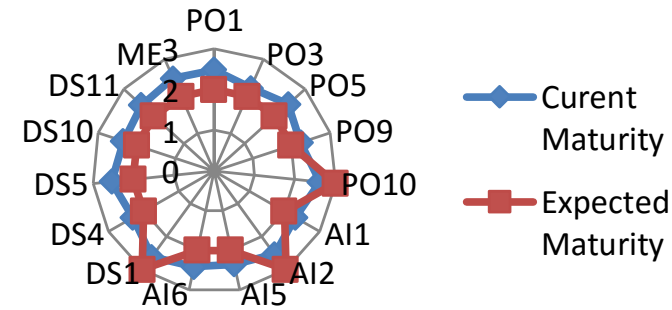

Gambar 3. Grafik Tingkat Kematangan

\section{KESIMPULAN}

Dari table yang ada sehingga bisa diambil suatu kesimpulan dari masing-masing domain yang ada yaitu Pada Domain PO (Plan and Organise) rata-rata tingkat kematangannya berada di level 2, Hal ini masih kecilnya kesadaran di PT.Surya Madistrindo atas kebutuhan prosedur dan kebijakan dasar terhadap akuisi TI prosedur dan kebijakan secara parsial terintegrasi dengan proses perolehan organisasi bisnis secara keseluruhan; proses pengadaan dimanfaatkan terutama untuk proyek yang sangat nyata $\&$ besar; sedangkan tingkat kematangan tertinggi pada PO10 yaitu manage Project.degan nilai rata-rata kematangannya 3.0 untuk menangani proyekporyek perusahaansudah baik.

Pada domain Acquire and Implement (AI), dapat dilihat pada 4 proses yang diteliti , 3 proses rata-rata berada pada level 2 (Define). Dalam hal ini perusahaan dalam memperoleh dan melaksanakan perusahaan masih belum terpola untuk merencanakan dan mengelola investasi teknologi informasi dan dilakukan secara berulang-ulang secara reaktif, namun belum melibatkan prosedur dan dokumen formal. Sedangkan dalam hal mendapatkan dan memelihara software aplikasi yang ada sudah baik karena ada pada tingkat kematangan 3.0 yaitu di AI2 - Acquire and maintain application software. Sedangkan tingkat kemtangan terkecil yaituAII - Identify automated solution dengan nilai kematangannya 2.306.Pada Domain Delivery and Support (DS) proses rata-rata pada level 2 dan hanya DS1- Define and 
manage service levels yang berada pada tingkat kematangan tertinggi yaitu 3.karena dalam hal ini perusahaan telah baik dalam menentukan dan mengelola tingkat layanan yang adaSedangkan untuk Domain Monitor and Evaluate $(M E)$ level tingkat kematnganya hanya 2. Dengan demikian bahwa tingkat kematangan yang ada pada PT.Surya Madistrindo berada pada tingkat 2 karena Kondisi dimana perusahaan telah kebiasaan yang terpola untuk merencanakan dan mengelola investasi teknologi informasi dan dilakukan secara berulang-ulang secara reaktif, namun belom melibatkan prosedur dan dokumen formal.

\section{PUSTAKA}

[1] Ade Roy Siagian.2010.Indonesian IT Governance,http://learncobit.blogspot.com

[2] Abiyoso, Gusrian. IT Governance dengan COBIT Framework, Universitas Bina Nusantara.

[3] ITGI 2005,IT Governance Institute, 'Management Guidelines and Audit Guidelines, Control Objectives”, COBIT $3^{\text {rd }} \quad$ ed. USA:ICASA, 2000, http://www.isaca.org

[4] Meadows, Rolling. 2002. Pembaharuan Utama Standar Internasional Dapat Menolong Bisnis Meningkatkan Nilai IT, Menurunkan Resiko. [Online]. Tersedia www.isaca.org/About-ISACA/Pressroom/News-Releases.

[5] Tarigan, Joshua. 2006. Merancang IT Governance dengan COBIT, Universitas Kristen Petra Surabaya

[6] Saraswati 2007,Saraswati, Sri, dkk, "Rancangan IT Governance untuk mendukung Unjuk Kerja Lembaga Penelitian Pemerintah", Jurnal Sistem Informasi MTI UI, http://jurnal.mti.cs.ui.ac.id

[7] Probonegoro, Wishnu. 2011. "Evaluasi Tata Kelola Teknologi Informasi dengan Menggunakan 15 Kerangka Kerja COBIT versi 4.0 : Studi Kasus SDN 3 Pangkalpinang”. Jurnal Informatika dan Komputer ATMA LUHUR. 02(2), 14-21 